\title{
Conflito e cooperação nas relações internacionais: as organizações internacionais no século XXI
}

\section{EIITI SATO*}

A recente intervenção anglo-americana no Iraque reacendeu o debate sobre a eficácia do direito internacional e das organizações internacionais. Dessa feita, muito mais do que em outras ocasiões em que a força foi empregada para resolver uma discórdia internacional, as reações contrárias à ação militar ficaram fortemente concentradas na alegação de que o ataque havia sido desfechado à margem de normas e princípios do direito internacional e que teria atingido gravemente a Organização das Nações Unidas (ONU) e tudo aquilo que a entidade representa para a ordem internacional na modernidade. Tecnicamente, contudo, foi apenas mais um evento internacional que expôs as características e limitações das organizações internacionais. O Estado moderno tem na soberania um de seus princípios fundantes e o estabelecimento de uma ordem capaz de acomodar esse princípio com as noções de justiça e de eqüidade tem sido um desafio para estadistas e pensadores nos últimos quatro séculos. É dentro dessa ótica de mais longo prazo que se afigura mais apropriado avaliar algumas perspectivas que se apresentam para as organizações internacionais nesse novo século. Um século que se inicia sob o impacto da ameaça de ataques terroristas em larga escala e da possibilidade real da maior potência do planeta escolher o unilateralismo como padrão predominante para sua política externa.

\section{A soberania e as limitações das organizações internacionais}

A existência de um Conselho de Segurança e o direito de veto reservado às grandes potências, reconhecendo explicitamente, portanto, uma hierarquia entre Estados no cenário internacional, foram condições que asseguraram a própria existência da ONU. Sem o instituto do veto, certamente teria sido muito mais difícil construir um consenso entre os Estados Unidos, a União Soviética e a GrãBretanha ao final da Segunda Guerra Mundial com vistas à criação da nova Organização. Esse dispositivo, no entanto, significa apenas a parte mais visível 
dos mecanismos contidos nessa entidade que limitam sua ação e que reconhecem uma condição distinta para as grandes potências. Na verdade, ao longo da existência da ONU há uma enorme lista de casos de conflitos internacionais que foram decididos ou conduzidos fora de seu âmbito.

Durante a guerra fria, o mecanismo do veto fez com que, sistematicamente, as questões mais críticas envolvendo a segurança internacional fossem tratadas e conduzidas à margem da entidade. Entre 1946 e 1990 o direito de veto foi usado 279 vezes pelos cinco membros permanentes do Conselho de Segurança. ${ }^{1} \mathrm{O}$ emprego de mais de 6 vetos por ano pelas grandes potências virtualmente significou o afastamento da possibilidade de um papel mais decisivo das Nações Unidas em questões internacionais que fossem efetivamente críticas. Se forem considerados os vetos não declarados, isto é, os casos em que uma potência, tendo consciência de que sua proposta de resolução seria objeto de veto por um dos cinco membros permanentes, tenha decidido não submeter a questão ao Conselho de Segurança, esse número seria ainda maior. Isso, no entanto, não significa que a ONU tenha fracassado e que não tenha tido um papel importante nas relações internacionais; significa apenas que seu alcance sempre foi limitado e que, tal como agora, há circunstâncias em que a diplomacia e as instituições não conseguem atingir plenamente seus objetivos e que as questões que afetam a soberania das nações continuam muito difíceis de serem manejadas.

Na verdade, freqüentemente se observa uma confusão quanto à natureza da Organização das Nações Unidas e suas finalidades. É certo que a promoção da paz constitui o objetivo básico da organização, todavia a entidade não se constitui num tribunal arbitral internacional mas sim numa instância diplomática multilateral. Nesse sentido, o uso do veto, inclusive na forma não declarada, não significa o fracasso da organização, significa isso sim que não existe consenso a respeito da questão em discussão. Significa que os mecanismos diplomáticos, inclusive aqueles oferecidos pela ONU, não são suficientes para a obtenção do consenso que tanto poderia significar dar apoio a uma intervenção militar ou encontrar alguma forma de solução pacífica.

Historicamente, essa é uma questão jamais resolvida nas relações internacionais. Não há uma fórmula para estabelecer os limites da noção de soberania em confronto com normas, princípios e instituições internacionais. A razão central reside no fato de que não há um padrão universal para os conceitos de justiça, de direitos e de obrigações entre sociedades e povos. Apesar de toda a retórica da globalização, continuam evidentes os sinais de que permanecem vivas as diferenças culturais e religiosas entre povos. Essas diferenças revelam mais uma entre as muitas facetas do paradoxo da própria existência humana: ao mesmo tempo que são essenciais para a preservação da multiplicidade e riqueza do fenômeno humano, também sustentam diferentes padrões de comportamento econômico, social e político, dificultando a compreensão mútua e a convivência. 
Os direitos individuais e os direitos da mulher, apenas para exemplificar, hoje se refletem tanto em normas jurídicas quanto em códigos de comportamento que não admitem a discriminação ou o cerceamento de direitos fundamentais como o de ir e vir, de ocupar cargos públicos ou de manifestar opiniões. Esse padrão, contudo, não se verifica em todas as sociedades consideradas civilizadas. Há sociedades em que esses direitos não são reconhecidos sob a alegação de que há razões religiosas ou culturais que fazem com que a existência individual das pessoas somente tenha sentido como parte de um grupo, um clã ou uma tribo.

Obviamente, não cabe aqui discutir essas diferenças, mas apenas observar que essa multiplicidade, característica do fenômeno humano, se reflete nas percepções sobre questões fundamentais como ordem, justiça e direitos que orientam os sentimentos morais e a ação política das sociedades e dos indivíduos. Robert Jervis, em seu livro escrito nos fins da década de 1960, argumentava que a imagem que os principais atores formam uns dos outros, assim como das circunstâncias, tem um papel decisivo nos eventos internacionais. ${ }^{2}$ No entender de Jervis, há aspectos sistêmicos, como a configuração da distribuição do poder ou o nível de institucionalização, que, efetivamente, influenciam os fenômenos internacionais; mas, além desses aspectos geralmente apontados pelos analistas, argumenta que o desencadeamento de crises bem como o seu manejo dependem também de crenças e percepções dos atores sobre objetivos, valores e riscos. Ideologias especialmente aquelas calcadas sobre crenças religiosas -, interesses econômicos ou disposição para correr riscos não influenciam de maneira uniforme as sociedades e as lideranças. Ao contrário, essas percepções vão constituir a base sobre a qual serão construídas as imagens que cada ator irá fazer acerca do ambiente internacional e dos demais atores com os quais eventualmente tem de interagir. Dessa forma, há um processo inevitável de formação de imagens díspares acerca dos fenômenos internacionais, o que deve, como conseqüência, produzir reações também diferentes. Cada ator tende a avaliar de forma diferente o significado de uma disputa comercial ou territorial, de um pacto de cooperação ou de um conflito armado real ou potencial. Nesse quadro, é inevitável o ambiente potencialmente conflitivo do meio internacional, uma vez que a noção de exercício da soberania, invariavelmente, é associada à idéia de que um Estado, para ser considerado efetivamente soberano, deve ter suas percepções transformadas em ação política.

Do ponto de vista da construção da ordem internacional, portanto, uma grande dificuldade reside na relutância dos Estados em ceder parte de sua soberania em favor de instâncias internacionais porque, inevitavelmente, essa atitude significa abrir mão, total ou parcialmente, da prerrogativa de transformar em ação política suas visões e percepções acerca do mundo e das coisas. Essa relutância pode ser maior em se tratando das grandes potências porque, ao admitirem uma instância internacional, podem estar abrindo mão da possibilidade de usar diretamente o poder de que dispõem para promover seus interesses. No entanto, isso não quer 
dizer que os Estados mais fracos também não vejam com desconfiança o surgimento de entidades internacionais poderosas. Seu receio é que essas entidades, em determinadas circunstâncias, venham a ser utilizadas como instrumentos de intervenção das grandes potências até mesmo em seus assuntos internos. Na história recente, a intervenção no Iraque foi apenas mais um entre muitos outros casos manifestos de relutância das grandes potências em outorgar maior poder para organizações internacionais, abrindo mão do uso do poderio de que dispõem para encaminhar, por via de uma instância internacional, uma solução para uma disputa envolvendo nações mais fracas. Na verdade, mais de trinta conflitos armados foram registrados ao longo das primeiras quatro décadas de existência da ONU e casos como o da Coréia, em 1950, e da Guerra do Golfo, em 1990, em que intervenções armadas contaram com a anuência formal do sistema Nações Unidas, constituíram-se em notáveis exceções. ${ }^{3}$ Na grande maioria dos conflitos, a participação da ONU, reconhecidamente importante, concentrou-se em esforços diplomáticos de mediação antes ou durante o conflito e em ações no sentido de assegurar condições de paz depois do cessar fogo, incluindo-se aí os trabalhos de reconstrução e assistência humanitária.

Por outro lado, uma vez que intervenções armadas tendem a ocorrer somente quando há ameaças reais ou presumidas à segurança das grandes potências, é no plano das relações econômicas onde se observa mais claramente a desconfiança das nações mais fracas em relação a organismos internacionais mais fortes. Instituições como o Fundo Monetário Internacional ou a Organização Mundial do Comércio são freqüentemente apontadas como potencialmente ameaçadoras às políticas nacionais e aos interesses dos países economicamente mais frágeis.

\section{A difícil trajetória das organizações internacionais}

Diante desse quadro, uma avaliação das organizações internacionais frente às perspectivas que se apresentam no contexto internacional neste início do século XXI deve ter por base o entendimento do significado fundamental dessas organizações e, para isso, deve-se incluir também uma breve reflexão sobre a experiência histórica vivida por essas entidades.

As organizações internacionais são a expressão mais visível dos esforços de cooperação internacional de forma articulada e permanente. Desde o surgimento do Estado Nacional como categoria política central nas relações entre povos e unidades políticas, a história registra a ocorrência de iniciativas de estadistas e formulações de pensadores voltadas para a estruturação de instituições que hoje chamamos de organizações internacionais. Mas, a história registra, igualmente, as enormes dificuldades de se por em prática essas iniciativas. 
Henrique IV e seu Ministro, o Duque de Sully, no início do século XVII portanto dentro de um ambiente político já formado por Estados Nacionais elaboraram a primeira proposta de formação de uma instância internacional centrada na idéia de um sistema de arbitragem permanente onde os soberanos deveriam resolver suas pendências sem o recurso da guerra. Cerca de um século depois, em 1712, Abbé de Saint-Pierre, retoma as idéias de Henrique IV numa proposta mais elaborada de um Projeto de paz perpétua. ${ }^{4}$ A grande preocupação dessas duas propostas era a de demonstrar, de um lado, as vantagens que as principais potências teriam em aderir ao projeto e, de outro, porque cada uma delas teria seus interesses fundamentais e sua autonomia respeitados. Rousseau, no entanto, ao ler a proposta de Abbé de Saint-Pierre argumentava que a proposta era realmente admirável em suas intenções e concordava também que seria vantajosa para todos os reinos, no entanto, observava com ceticismo o comportamento dos governantes e concluía que "embora admiremos um projeto tão belo, devemos consolar-nos do seu fracasso uma vez que só poderia ser implantado (justamente) com os meios violentos que a humanidade precisa abandonar”. É possível que se a proposta de Henrique IV ou de Abbé de SaintPierre não presumissem a constituição de uma instância que se constituísse num tribunal arbitral entre as nações, mas tão somente numa entidade política onde os Estados procurassem discutir e negociar suas demandas, sua aceitação seria menos problemática.

Com efeito, cem anos depois, ao final das guerras napoleônicas, as grandes potências, lideradas por Metternich e Castlereagh, constituíram o Concerto Europeu. Esse arranjo não apresentava, nem de longe, o grau de institucionalização contido na proposta de Abbé de Saint-Pierre e nem tinha a pretensão de se constituir num tribunal arbitral internacional. Os reinos, especialmente os mais poderosos, manteriam sua soberania de forma plena, aceitando apenas a idéia de que suas demandas poderiam ser discutidas em encontros de governantes e de plenipotenciários e que a busca do consenso passaria a figurar entre os objetivos da diplomacia. O Concerto Europeu, portanto, apresentava um nível muito baixo de institucionalização e, formalmente, seus participantes praticamente não tinham qualquer obrigação, dever ou mesmo custo derivado de sua participação no arranjo, a não ser o de discutir suas demandas com as demais potências.

No Continente Americano, as mesmas dificuldades de conciliar a natureza das organizações internacionais com as aspirações de soberania também se fizeram presentes numa das iniciativas mais notáveis do processo de independência da região. A idéia de Bolívar para constituição de uma Confederação de Estados Americanos não foi além do Congresso de 1826, que contou com a presença de apenas alguns representantes de países americanos. Entre as várias razões que podem ser apontadas para esse fato, além da baixa densidade na interação entre os novos Estados que acabavam de se formar na região e que tinham muito pouco 
interesse nas relações com os vizinhos, pode-se destacar a ausência dos Estados Unidos, que não foram convidados, em grande parte pela preocupação de Bolívar em não despertar a oposição da Grã-Bretanha. Essa ausência teria, por outro lado, contribuído para a ausência de outras nações que temiam que um arranjo daquela natureza, que virtualmente excluía os Estados Unidos, pudesse despertar a desconfiança da jovem potência regional em relação à formação de uma liga anti-americana. ${ }^{5}$

Um século mais tarde a Liga das Nações iria se constituir na primeira organização internacional de forma plena e no sentido atual. A história de sua curta e turbulenta trajetória, no entanto, é conhecida. J. M. Keynes, em seu livro As conseqüências econômicas da paz, ${ }^{6}$ ainda sob o impacto da decepção sofrida na Conferência de Versailles, relata de forma eloqüente como a atitude de Lloyd George e Clemenceau, notadamente egoísta em termos do que entendiam serem os interesses dos Estados que representavam, comprometeram o destino da Liga das Nações desde seu nascimento. Lloyd George e Clemenceau não eram vilões ou estadistas irresponsáveis, mas apenas refletiam a percepção corrente entre políticos e até mesmo entre estudiosos que acreditavam (muitos continuam acreditando até hoje) que estavam somente cumprindo seu papel de defender aquilo que julgavam ser o interesse de seus países e que, como bons defensores, deveriam valer-se de seus talentos individuais e dos recursos de poder de que dispunham de forma que decisões e arranjos que emergissem daquele encontro contemplassem esses interesses, se possível, em sua plenitude. A Liga era entendida muito mais como um instrumento de afirmação de soberania dos Estados do que como uma instância internacional com capacidade de encaminhar soluções para as eventuais disputas internacionais. Até mesmo o Brasil foi protagonista de um evento marcante que, na história da Liga, revela as contínuas dificuldades originadas do desejo de afirmação das soberanias, que se choca com freqüência com os requisitos de uma autoridade tipicamente supra-nacional. Com efeito, as negociações de Locarno, de 1925, que levaram a Alemanha a integrar a Liga em 1926, com direito a um assento permanente no Conselho da entidade, foram vistas nas capitais européias como um enorme passo em direção à construção de uma paz estável. $\mathrm{Na}$ avaliação das principais lideranças européias, os acordos de Locarno teriam sido o verdadeiro epílogo para as questões mal resolvidas na Conferência de Paz de Versailles. No entanto, o Governo Brasileiro, sentindo-se virtualmente traído no seu intuito de tornar-se membro permanente do Conselho da organização, decide, num gesto grandiloqüente, retirar-se da entidade. ${ }^{7} \mathrm{Na}$ essência, do ponto de vista da construção da ordem internacional, o que o Governo Brasileiro havia manifestado no episódio era apenas mais um testemunho vivo dos limites bastante estreitos da parcela de soberania que as nações estão dispostas a ceder em favor de instâncias internacionais. 


\section{A eficácia das organizações internacionais}

Essas considerações, contudo, não querem dizer que as organizações internacionais não tenham sua eficácia e que sejam instâncias diplomáticas de pouca importância, que ocultam sob um manto de amenidades e conveniências apenas uma fria e incansável luta pelo poder. Essas considerações pareceram necessárias para lembrar que os esforços de construção de uma ordem internacional pacífica e articulada é uma tarefa difícil e trabalhosa porque precisa conciliar percepções e anseios políticos contraditórios. O estabelecimento de normas internacionais não traz em si a garantia de que essas normas serão efetivamente cumpridas e que uma vez produzidas, automaticamente, farão surgir padrões de comportamento. Mesmo no plano doméstico, onde existe uma autoridade formalmente constituída e amplamente estruturada, o fato de produzir leis não significa que direitos humanos sejam plenamente respeitados, padrões ambientais sejam observados ou que crimes deixem de ser cometidos ou que sejam devidamente punidos: o poder judiciário pode ser lento e ineficaz e a polícia pode ser corrupta ou insuficiente para fazer com que as leis, novas ou antigas, sejam cumpridas. A esse respeito, no caso do Brasil, diariamente há incontáveis exemplos. No plano internacional, onde as normas são compostas basicamente de tratados, onde não há uma autoridade supranacional independente dos Estados (que possuem o atributo da soberania) e onde a principal forma de sanção é a condenação moral, a existência e a eficácia de arranjos e instituições continuam fortemente dependentes das percepções e da vontade de agir dos governantes dos Estados.

Apesar de tudo, é possível apontar vários fatos e desenvolvimentos que indicam que as organizações internacionais têm sido muito eficazes e hoje fazem parte integrante da vida das sociedades. Na verdade, embora na maioria das vezes de forma pouco visível, são elementos essenciais da modernidade. Atualmente, é inimaginável um mundo sem o enorme fluxo de bens, recursos financeiros, informações, pessoas e de uma série de outros elementos mais difusos e menos quantificáveis que transitam continuamente entre as fronteiras que delimitam os Estados. Na base desse fenômeno, está uma ampla e complexa malha de organizações internacionais, que, de maneira integrada, possibilita esse fluxo relativamente ordeiro e continuamente crescente.

Um aspecto central, geralmente pouco lembrado, a ser assinalado, é o fato de que, embora as organizações internacionais geralmente sejam voltadas para uma determinada área das relações internacionais, elas exercem influência significativa sobre todas as demais. Assim, as relações comerciais não se ligam apenas com as relações financeiras e monetárias, mas têm conexões estreitas com áreas técnicas, culturais e mesmo de segurança internacional, e a história exibe vários exemplos em que essa interligação foi particularmente importante. 
Com efeito, as principais iniciativas que resultaram na construção da ordem econômica que se seguiu à Segunda Guerra Mundial tiveram por base essa associação de objetivos. O Plano Marshall, em larga medida, foi uma solução keynesiana para os problemas da estagnação econômica que atingia a Europa e que ameaçava se estender para os Estados Unidos. Keynes, em Bretton Woods, havia insistido em vão na necessidade de os Estados Unidos proverem a economia internacional (isto é, a Europa) de dólares. Em 1947, os Estados Unidos, sob nova liderança e movidos pela estratégia de construção de um sistema de segurança internacional baseado no containment (contenção do avanço soviético), produziram o Plano Marshall, que transferiu para a Europa aproximadamente a mesma quantia que Keynes havia apontado, com argumentos econômicos, como necessária para resolver o problema da falta de liquidez da economia internacional. A formação dos arranjos que fizeram parte do processo de integração européia e muitas outras iniciativas que deram os contornos do mundo do pós-guerra obedeceram uma lógica semelhante. Ou seja, os argumentos originados das formulações estratégicas sobre segurança internacional conseguiram ser eficazes onde os argumentos de Keynes, fundados na teoria econômica, por mais sensatos e coerentes que tenham sido, haviam fracassado.

O caso do comércio é muito ilustrativo dessa evolução das organizações internacionais e também de como sua importância transcende os limites estritos das trocas comerciais e, de modo geral, das transações econômicas. Pensadores como Montesquieu e Kant dedicaram atenção ao que ficou conhecido como a “tese do suave comércio”. Montesquieu, no Espírito das Leis afirma: “O efeito natural do comércio é trazer a paz. Duas nações que comerciam juntas tornam-se reciprocamente dependentes; se uma tem interesse em comprar, a outra em vender; e todas as uniões estão baseadas nas mútuas necessidades". ${ }^{8} \mathrm{O}$ acesso a matériasprimas essenciais, em várias circunstâncias, revelou essa face "pacificadora” do comércio e, com certeza, essa tese hoje poderia ser estendida a muitas outras áreas: turismo, ciência e tecnologia, cultura, etc. Obviamente, no sentido inverso, dificuldades e ameaças ao acesso a fontes de matérias-primas essenciais também podem se constituir em fatores de instabilidade e até mesmo em ameaças à segurança internacional.

Nas cinco décadas que se seguiram ao final da Segunda Guerra Mundial, os inúmeros arranjos globais, regionais e setoriais desempenharam um papel essencial no processo de evolução do comércio até os níveis atuais. No plano mais geral é notável como a criação do Gatt, com todas as suas limitações, ajudou a estabelecer as bases da recuperação dos fluxos comerciais nas duas primeiras décadas do pós-guerra. A partir dos anos 1980, contudo, o mundo passou a enfrentar dificuldades para continuar incrementando o comércio internacional e, afinal, percebeu-se que essas dificuldades decorriam, em grande medida, do baixo 
nível de institucionalização do Gatt. Os impasses que apareceram de forma marcante na Rodada Uruguai de negociações comerciais, iniciada em 1986, evidenciavam as dificuldades de obtenção de consenso entre nações e blocos econômicos que disputavam espaço nos mercados internacionais. A emergência da Europa, do Japão e de outras economias em setores específicos havia minado a capacidade dos Estados Unidos de arbitrar disputas comerciais enquanto as regras difusas do Gatt se revelavam incapazes de atuar com eficácia dentro do novo cenário dentro do qual o comércio internacional passava a se mover. A solução encontrada para esses impasses foi a transformação do Gatt em OMC (Organização Mundial do Comércio), uma entidade com perfil institucional muito mais definido e com capacidade de, efetivamente, intervir na autonomia das ações dos Estados no que tange às políticas comerciais. Apesar de eventuais manifestações de insatisfação, não há dúvida de que o sistema de solução de controvérsias da OMC, com suas peculiaridades e imperfeições, funciona como um verdadeiro tribunal arbitral internacional permanente para as questões do comércio e que essa transformação de um Gatt, feito de regras difusas, para uma OMC, com capacidade para orientar e resolver disputas comerciais, é fruto de um significativo consenso internacional.

Obviamente, as questões de comércio apresentam um perfil muito menos crítico do que aquelas que dizem respeito diretamente à segurança e ao poder das nações. Entretanto, é importante notar que as crises internacionais podem ter origem variada e geralmente são o resultado de desentendimentos sobre diversas questões que se combinam agravando-se mutuamente. Além disso, a questão do acesso a fontes de matérias-primas e aos meios de construir e acumular riqueza sempre tiveram papel fundamental na definição de políticas internas e externas. Dessa forma, somente o que ocorreu no mundo do comércio já seria suficiente para justificar o argumento de que há muito mais sucesso do que fracasso a ser registrado na história das organizações internacionais e é possível identificar trajetórias semelhantes nas finanças, nas relações monetárias, na ciência e tecnologia e em muitos outros campos da cooperação internacional, que, de muitas maneiras, têm construído pontes de relacionamento e de entendimento entre povos e nações. Muito provavelmente esses desenvolvimentos já foram muito além do que Montesquieu, Kant e outros pensadores da tradição do "suave comércio” um dia imaginaram.

\section{As organizações internacionais no século XXI em perspectiva}

O esforço de elaborar uma visão sobre o futuro é sempre condicionado, de um lado, pela experiência histórica e, de outro, pela impossibilidade de prever desenvolvimentos inesperados. Apesar de tudo, pode-se estabelecer alguns 
possíveis desdobramentos a partir das atuais circunstâncias e algumas dificuldades a serem enfrentadas nos próximos anos pelas organizações internacionais.

De uma forma geral, como já foi destacado anteriormente, as relações internacionais tornaram-se uma dimensão inerente à vida civilizada na modernidade e essa dimensão depende de muitas formas do bom funcionamento de uma ampla rede de organizações internacionais, sendo praticamente impossível pensar numa alternativa a essa possibilidade que não esteja associada a uma drástica deterioração das condições de vida na atualidade. Isto é, qualquer recuo nessa tendência parece inevitavelmente associado a elevação dos níveis de intolerância e a outras circunstâncias dramáticas que representariam um verdadeiro recuo nos padrões de convivência civilizada da humanidade. Os níveis de bem estar de que hoje desfrutam as sociedades dependem de forma significativa das muitas maneiras pelas quais indivíduos e instituições interagem no plano internacional. Para a maioria dos países ricos a renda nacional depende em um terço ou mais do comércio exterior. Economias importantes como a da Alemanha, da França, da Grã-Bretanha ou da Holanda dependem em mais de $40 \%$ do comércio com outros países. O volume total do comércio internacional supera hoje a casa dos US\$ 10 trilhões e calcula-se que os fluxos financeiros internacionais sejam cem vezes maior. Obviamente essas são apenas algumas cifras mais visíveis, mas há inúmeras outras formas pelas quais o modo de vida na modernidade e os níveis de bem estar dependem de forma substancial da interação internacional.

No plano mais específico das organizações internacionais não é possível analisar as perspectivas que se apresentam individualmente para essas entidades. Todavia, é possível identificar algumas forças ou tendências que atuam sobre a ordem internacional e que devem influenciar o futuro das organizações internacionais.

Em primeiro lugar, as organizações internacionais são organismos vivos que se transformam ao longo do tempo acompanhando as mudanças sociais e políticas. Desde 1945 a Organização das Nações Unidas vem passando por mudanças seja no número de países membros, que se tornou praticamente quatro vezes maior, ou de suas atribuições, que passaram a incluir uma grande quantidade de novos itens em sua agenda de preocupações. Uma possível reforma da ONU, que incluiria mudanças na composição do Conselho de Segurança, tem se revelado um empreendimento particularmente difícil. Muito embora haja consenso de que a composição atual do Conselho de Segurança não reflete mais as necessidades da ordem internacional, as alternativas de reforma apresentam inúmeros aspectos controvertidos, difíceis de serem superados. Por exemplo, se forem mantidas as atuais regras e se forem atendidas todas as demandas (somente as mais significativas e representativas) o número de países com direito a veto pelo menos dobraria, dificultando ainda mais o processo decisório e a capacidade de ação efetiva da Organização em situações de crise. Por outro lado, entre os possíveis 
"candidatos naturais" a ocuparem uma vaga permanente no Conselho de Segurança, talvez o Brasil seja um dos casos menos controvertidos no momento, mas dificilmente seria feita a inclusão isolada de qualquer novo país como membro permanente do Conselho de Segurança. Além disso, outras instâncias como o G-8, por exemplo, também se apresentam, sob muitos aspectos, como instâncias alternativas para o encaminhamento de muitas questões mundiais. Alguns problemas globais como aqueles relacionadas ao meio ambiente e à proteção dos direitos humanos bem como à ajuda humanitária tiveram avanços institucionais consideráveis nas últimas décadas e, muito embora possam eventualmente sofrer alguns percalços e até mesmo recuos, a natureza dessas questões e suas implicações para o bem estar e para a ordem política indicam que deverão continuar avançando, seja no âmbito do sistema Nações Unidas ou fora dele. Arranjos informais como o G-8 podem ter um papel de grande importância na construção de consensos sobre questões importantes para a ordem internacional.

No campo das relações econômicas internacionais, o Fundo Monetário Internacional de hoje tem muitas características ou funções que não existiam quando de sua criação, enquanto muitas daquelas para as quais fora criado, como a de ser a principal instituição responsável pela administração da liquidez internacional, virtualmente deixaram de existir. O manejo do equilíbrio entre as economias hoje depende apenas parcialmente dos instrumentos de ação do FMI, ao mesmo tempo em que a instituição foi, gradativamente, assumindo um curioso papel de auditor internacional das contas internas e externas dos países endividados. Essa transformação ocorreu em grande parte porque os desequilíbrios nos balanços de pagamento cresceram a tal ponto que tornaram irrisórios os recursos e os mecanismos do FMI para manejar esses desequilíbrios. Na verdade, desde a sua fundação, os recursos postos à disposição do Fundo pelo mecanismo de quotas sempre foram insuficientes para enfrentar situações de desequilíbrio mais graves, e o crescimento da economia internacional apenas agravou essa insuficiência. Os empréstimos do Fundo ainda continuam servindo para equilibrar as contas externas dos países, mas apenas quando esses desequilíbrios são relativamente pequenos e ocasionais. Em situações mais críticas, geralmente decorrentes não de desequilíbrios comerciais mas de crises financeiras, o Fundo tem atuado como principal elemento catalisador de empréstimos de fontes variadas e não como provedor de fundos para estabilizar economias em dificuldades.

Sob muitos aspectos essas mudanças no papel desempenhado pelo FMI deverão estar associadas a desenvolvimentos que venham a ocorrer no atual quadro do sistema monetário internacional e esse é um quadro difícil de prever. A força do dólar americano e a afirmação do euro como moeda internacional são apenas duas entre as muitas variáveis que deverão influenciar a conformação do sistema monetário internacional nos próximos anos. Mas, a economia internacional é muito dinâmica e há outros desenvolvimentos em curso na ordem econômica e política 
que podem produzir mudanças inesperadas. De uma forma geral, no entanto, é possível entender que mesmo que a economia americana continue com seu papel de principal economia do mundo, outros centros de poder continuarão a emergir e aumentar sua importância relativa dentro do sistema, fazendo com que o Fundo Monetário Internacional, provavelmente reforçado por outras instâncias como o G-8, o Forum Econômico Mundial, o Bank for International Settlements e o próprio Banco Mundial, tenha, cada vez mais, um papel de coordenação e de construção de consensos.

No campo do sistema financeiro internacional não é muito diferente. As mudanças sofridas refletem, de um lado, mudanças bastante radicais na concepção da cooperação internacional para o desenvolvimento e, de outro, o reordenamento dos fluxos financeiros a partir da desregulamentação e do revigoramento dos mercados privados de capitais. O Banco Mundial, que um dia tivera o papel de elemento central do sistema, como instituição tipicamente intergovernamental, também vem reorientando seu papel e suas atividades.

Até meados dos anos 1970, a cooperação financeira internacional era entendida essencialmente como fomento a projetos de desenvolvimento que, notadamente, incluía a construção de infra-estrutura econômica a partir da premissa de que havia um considerável número de países cuja pobreza derivava fundamentalmente da idéia de que eram economias carentes de poupança interna e que nos capitais externos estaria a chave para a industrialização e o desenvolvimento. Recursos do Banco Mundial e de agências de fomento ao desenvolvimento regionais e bilaterais eram destinados a esses países mediante projetos que demonstrassem seu potencial de geração de atividade econômica. Nessa estratégia, as economias centrais (em especial os Estados Unidos), por sua vez, se beneficiariam de duas formas: primeiro, pela venda de equipamentos e outros produtos necessários ao processo de industrialização das economias periféricas e, em seguida, com o avanço da modernização, esses países poderiam se tornar mercados cada vez mais importantes. Contudo, essa estratégia de atuação foi, pouco a pouco, sendo abandonada diante de alguns desenvolvimentos observados a partir dos anos 1970.

A crise do petróleo, ao produzir um ambiente de recessão internacional, trouxe consigo uma redução substancial na disponibilidade de recursos para programas de fomento ao desenvolvimento. Além disso, a crise pôs a descoberto o fato de que a carência de poupança interna não era suficiente para explicar a falta de recursos para investimentos nas sociedades pobres. Os países da Opep, na esteira dos sucessivos aumentos de preço do petróleo, receberam uma maciça transferência de recursos internacionais, muito maior do que os países da Europa haviam recebido com o Plano Marshall. Dados do Conselho Nacional do Petróleo (CNP) mostram que o Brasil, por exemplo, em 1973, ano em que foi deflagrado o primeiro choque nos preços do petróleo, gastou US\$ 947 milhões com a importação 
de petróleo. No ano de 1974 esses gastos haviam se elevado para US\$3,15 bilhões ${ }^{9}$ e essas cifras já atingiam a quantia de US\$ 10 bilhões na virada daquela década. Nessa época cerca de $90 \%$ das importações de petróleo feitas pelo Brasil vinham do Oriente Médio. Apesar de tudo, não se observava nenhum resultado significativo em termos de desenvolvimento econômico que beneficiasse de forma geral a população desses países. Em sua maior parte, os recursos que afluíam de forma maciça para os países exportadores de petróleo tinham outro destino. Além do aumento do consumo conspícuo das elites e de compras de armamentos, o que se verificou foi o re-investimento da maior parte dos saldos dos petrodólares no sistema financeiro internacional. Posteriormente, a crise do endividamento do Terceiro Mundo dos anos 1980 foi mais um fato que contribuiu significativamente para alterar a percepção do significado da cooperação internacional para o desenvolvimento, contido nas estratégias de ação dessas instituições de fomento, notadamente do Banco Mundial. A crise da dívida tornava evidente que a estratégia de crescimento havia se esgotado. Os programas de fomento sofreram drásticas reduções e reorientaram suas prioridades passando a contemplar principalmente projetos voltados para áreas como a promoção da saúde pública, a recuperação e preservação de recursos ambientais e a proteção e promoção de minorias.

Entidades como o FMI e o Banco Mundial não deverão deixar de existir num futuro próximo, mas com certeza deverão continuar sofrendo mudanças em face de transformações como, por exemplo, um possível fortalecimento da União Européia e do euro como moeda internacional importante, ou de um novo papel para a economia asiática. Além disso, a evolução de iniciativas como a Área de Livre Comércio das Américas (Alca) pode ter um papel significativo na conformação de novos perfis para a cooperação econômica internacional. As incertezas quanto à implantação da Alca residem em vários pontos e não apenas numa possível aceitação por parte dos Estados Unidos de demandas do Brasil e de outras economias importantes da região. Um aspecto sempre importante a ser considerado é o fato de que a perspectiva dos Estados Unidos é, antes de mais nada, uma perspectiva mundial para quem a política internacional se confunde com os interesses nacionais e regionais. Dessa forma, é inevitável que dificuldades e benefícios advindos da evolução da ordem internacional tenham reflexos diretos sobre o desempenho de arranjos regionais de que os Estados Unidos façam parte. No passado, as economias mais diretamente relacionadas com a Grã-Bretanha se beneficiaram de ciclos de crescimento daquela potência, no entanto, quando as dificuldades surgiam na ordem econômica internacional, considerável parte do esforço adicional da Grã-Bretanha para manter seu papel de economia central do sistema monetário e financeiro, invariavelmente, recaía sobre sua periferia mais próxima. Por outro lado, mesmo sem a constituição da Alca, os Estados Unidos já são há muito tempo, individualmente, o parceiro comercial e financeiro de maior peso para o Brasil e para outras economias da região e, dessa forma, os efeitos 
estabilizadores ou desestabilizadores da economia americana sobre a região ocorrerão de qualquer forma.

Uma questão mais geral afeita a todas essas organizações, incluindo-se a própria ONU, é a questão da distribuição das responsabilidades internacionais. Paz, estabilidade, crescimento econômico e, mais recentemente, preservação das condições ambientais do planeta são bens cujo provimento, bem como seu usufruto, obedecem a mesma lógica de todos os bens públicos: os atores tendem a ser free riders quanto ao provimento desses bens públicos, uma vez que seu usufruto não pode ser particularizado e restrito apenas àqueles que presumivelmente teriam pago por esses bens. Nesse quadro, talvez a pergunta mais fundamental a ser respondida nesses próximos anos é saber até que ponto as nações, sobretudo as grandes potências, incluindo-se os Estados Unidos, estão dispostas a participar de um esforço de concertação internacional e de construção efetiva de uma ordem que contemple as demandas por paz e progresso da grande maioria das sociedades organizadas do mundo. Obter um consenso a respeito dessa questão é muito difícil; significa aceitar regras de convivência e também custear os arranjos institucionais que se fizerem necessários. De uma forma geral, todas as nações defendem o multilateralismo, argumentam em favor do desenvolvimento de formas de convivência pacífica e se mostram cooperativas a menos que, de alguma forma, surja uma circunstância em que, no seu entender, algum interesse fundamental está em jogo. O grande problema é definir esse interesse fundamental e fazer com que outros compreendam a questão da mesma maneira. Além disso, por que as dificuldades circunstanciais de uma potência não deverão ser interpretadas e manejadas como oportunidades e vantagens para outras nações?

Nesse processo, um eventual fracasso de uma negociação acerca de uma questão internacional não pode ser entendido como o fracasso de todo um sistema ou a impossibilidade de se promover um tema de interesse para a convivência internacional. A constituição de instâncias internacionais não é um processo simples e também não é linear. Está sujeito a turbulências e muitas vezes a recuos. Sucesso ou fracasso não podem ser identificados apenas pela criação ou abandono de um foro de negociação. Essas são apenas a parte visível do trabalho e do produto da diplomacia multilateral, com suas limitações e com sua característica fundamental, que é a continuidade. Com efeito, há objetivos e interesses conflitantes e concorrentes que se alteram ao longo do tempo e que são difíceis de serem acomodados, suscitando continuamente questões nada fáceis de serem respondidas a não ser pela ação política tolerante e paciente. A autoridade é necessária para manter a ordem internacional, mas como construir essa autoridade se ela depende diretamente da decisão política dos Estados?

As respostas dependem de visões por vezes bastante díspares e acomodálas não é tarefa fácil. Os avanços conseguidos até o momento não são suficientes, 
mas são bastante significativos quando vistos sob a ótica da história. A paciência e a tolerância são valores que a cristandade aprendeu a valorizar porque sofreu tanto o peso de perseguições e martírios quanto a tragédia de perseguir cruelmente uns aos outros. Locke, em fins do século XVII, dedicou uma importante reflexão em favor da tolerância entre cristãos, ${ }^{10}$ mas essa era uma época em que, para os europeus, o mundo praticamente se confundia com a Europa. Hoje a diversidade é muito maior e, apesar de todos os avanços nas tecnologias de comunicação e da retórica da globalização, o entendimento entre povos e nações continua um desafio. David Hume argumentava que nossos julgamentos em qualquer área, apesar do contínuo esforço de buscar suporte na razão, em última instância, se fundam essencialmente nos sentimentos humanos. ${ }^{11}$ Esses sentimentos são cambiantes e variam de acordo com percepções fundadas em ideologias e visões sobre riscos, interesses e oportunidades. Nesse quadro, construir e participar de instituições internacionais é uma das formas mais valiosas de aprimorar a convivência humana em nosso tempo, mas também não se pode esquecer de que essa é uma dedicação que exige, antes de mais nada, um exercício continuado de paciência e tolerância.

Junho de 2003

\section{Notas}

1124 vezes pela União Soviética; 82 pelos Estados Unidos; 33 pela Grã-Bretanha; 22 pela China; e 18 pela França (FUJITA, E. O Brasil e o Conselho de Segurança. Parcerias Estratégicas. Vol. 1, n. 2, dez. 1996. p. 96.)

2 JERVIS, Robert. The logic of images in international relations. New Jersey: Princeton University Press, 1970.

3 LUARD, E. Conflict and peace in the modern international system. A study of the principles of international order. Macmillan Press \& State University of New York, 1988. SAINT-PIERRE, Abbé de. Projeto para tornar perpétua a paz na Europa. Brasília: IPRI/ FUNAG, Editora Universidade de Brasília; São Paulo: Imprensa Oficial do Estado de S. Paulo, 2003.

5 FENWICK, C. G. A Organização dos Estados Americanos. O sistema regional interamericano. Rio de Janeiro: Edições GRD, 1965.

6 KEYNES, J. M. As Conseqüências Econômicas da Paz. Brasília: IPRI/FUNAG, Editora Universidade de Brasília; São Paulo: Imprensa Oficial do Estado de S. Paulo, 2002.

7 GARCIA, E. V. O Brasil e a Liga das Nações (1919-1926). Porto Alegre: Ed. da UFRGS, 2000.

8 MONTESQUIEU. O Espírito das leis. Livro 20, cap. II. p. 358. Brasília: Editora Universidade de Brasília, 1982. Sobre a tese do "suave comércio", ver também HIRSCHMAN, A. O. A Economia como Ciência Moral. São Paulo: Editora Brasiliense, 1986.

$9 \quad$ SINOPSE ESTATÍSTICA DO BRASIL. Rio de Janeiro: Fundação IBGE, 1977. p. 321-2. Os preços do barril de petróleo passaram de US\$ 1,85 para US\$ 4,76 em outubro de 1973 e, em janeiro de 1974, já atingia US\$10,96. 
10 LOCKE, J. Essay concerning human understanding. 1690.

11 HUME, D. Essays: moral and political. 1741.

\section{Resumo}

Partindo da recente intervenção anglo-americana no Iraque, o presente artigo inicia um debate acerca do papel desempenhado pelas organizações multilaterais no mundo atual. Questionando inicialmente a real eficácia dessas organizações, o autor conclui que seu processo de consolidação não é linear, estando sujeito a retrocessos, mas afirma que a continuidade da diplomacia multilateral não pode ser abandonada.

\section{Abstract}

Departing from the recent Anglo-American intervention in Iraq, this article inaugurates a debate regarding the role played by the multilateral organizations in today's world. Initially questioning the real efficiency of these organizations, the author infers that its process of consolidation is not linear, being subject to retrocessions, but affirms that the continuity of multilateral diplomacy cannot be disregarded.

Palavras-chave: Organizações Internacionais; ONU; Gatt; Alca. Key words: International Organizations; UN; Gatt; FTAA. 